\title{
Synthesis and electro-optical properties of fluorene containing blue luminescent rod-coil homopolymers with pendant pyridine
}

\author{
DURYOdHAN SAHU ${ }^{1, *}$, SUbHENDU CHAKROBORTY ${ }^{2}$ \\ ${ }^{1}$ Department of Chemistry, National Institute of Science and Technology, Palurhills, Berhampur, Odisha, 761008, India \\ ${ }^{2}$ Department of Chemistry, Indian Institute of Technology, Indore, Simrol, Khandwa Road, 452020, India
}

\begin{abstract}
Two well defined, blue luminescent homopolymers containing 9,9-diethylfluorene core with electron withdrawing pendant pyridine, Suzuki-coupled with the corresponding borolane of decoxy phenyl (PFPA) and naphthalene (PFNA) have been designed and synthesized efficiently. The obtained rod-coil polymers have the average molecular weight of 15212 (PFPA) and 15130 (PFNA) with polydispersity indices (PDIs) 1.07 and 1.3, respectively. The polymers have good solubility and high thermal stability with the decomposition temperature of $362{ }^{\circ} \mathrm{C}$ (PFPA) and $367^{\circ} \mathrm{C}$ (PFNA) correspondingly. Furthermore the optical and electrochemical properties of the polymers have been investigated. The polymers exhibited photoluminescence (PL) maxima at $410 \mathrm{~nm}$ (PFPA) and $414 \mathrm{~nm}$ (PFNA) excited at $340 \mathrm{~nm}$, as stable blue luminescence polymers at low concentration of $10^{-6} \mathrm{M}$ with a quantum yield of 0.64 and 0.62 , respectively. In addition the annealed $\left(150^{\circ} \mathrm{C}\right)$ polymer films showed better stability of its photoluminescence spectra. Absorbance and fluorescence emission spectra of PFPA and PFNA were compared in order to evaluate the effects of substituent, phenyl and naphthalene in pyridine pendant fluorene moieties.
\end{abstract}

Keywords: radical polymerization; blue luminescence; rod-coil homopolymer; fluorene; electro-optical properties

(C) Wroclaw University of Science and Technology.

\section{Introduction}

Synthesis of organic materials bearing extended $\pi$-conjugation have captured immense attention in recent years owing to their unique photophysical properties which make them promising materials for diversified applications including organic light-emitting diodes (OLEDs) [1], organic photovoltaics (OPV) [2], organic thin film transistors (OTFT) [3], sensors etc. After the discovery of electroluminescence in a polymeric semiconductor, a large effort has been made to synthesize polymers with different chromophoric moieties which make OLED-based technology a possible alternative to liquid crystal-based displays. Lately, considerable progress has been documented in several papers to develop OLED displays for other niche lighting applications $[4,5]$. Red, green,

*E-mail: duryosahu@gmail.com and blue emitters are the prime requirements for the fabrication of full-color displays. The stability and efficiency of green and red emitters have approached commercially viable levels [4-7]. The search for blue luminophores with high emission efficiency is a subject of current interest, as they are essential in high quality full color displays and white lighting $[8,9]$. To respond to the rising demand, various blue luminophors derived from fluorene [10, 11], anthracene [12], pyrene [13] and carbazole [14] have been designed and studied, some of which have promising prospect in efficient blue OLEDs.

In the past decade, synthesized fluorene-based conjugated polymers have emerged as a very promising class of luminophoric compounds for the use in polymer light emitting diodes (PLEDs) because of their high PL and electroluminescence quantum efficiencies, easy film forming, thermal stability, good solubility, facile functionalization 
at the C-9 position of fluorene and ready colortuning through the introduction of low-band-gap co-monomers. It is a rigid and planar molecule, and the electronic and optical properties arise from its planarity, while the rigidity improves the thermal stability by prohibiting free rotation around the 1-1" bond of the biphenyl. Several mono-, oligo-, or polyfluorenes [15-23] have been synthesized to substantiate their potential for preparing blue organic light emitting diodes with high quantum efficiencies.

Herein, we synthesized two rod-coil homopolymers containing three conjugated aromatic rings, a pyridyl terminus followed by 9,9 ' alkylated chromophoric fluorene and phenyl/naphthyl extended with decoxy via Suzuki-coupling reaction and subsequent free radical polymerization using AIBN. The extended decoxy groups in the conjugated segments imparted the resulting polymers with excellent solubility and film-forming abilities. In contrast to fluorene, the polymers showed good thermal stability and exhibited stable blue luminescence at low concentrations. Furthermore, owing to the tuned rod-coil structure and longer conjugation length the polymers showed unique optical and electrochemical properties which could be applicable for various electro-optical applications. Absorbance and fluorescence emission spectra were compared in order to evaluate the effects of substituent phenyl and naphthalene in fluorene moieties containing pyridine at pendent.

\section{Experimental}

\subsection{Materials}

All the chemicals used in this work were purchased from Aldrich, ACROS, TCI, Strem, Fluka, and Lancaster Chemical Co. THF and dichloromethane were distilled over sodium/benzophenone and calcium hydride respectively. Tetra-n-butyl ammonium hexafluorophosphate $\left(\mathrm{TBAPF}_{6}\right)$ was recrystallized twice from absolute ethanol and further dried for two days under vacuum. The other chemicals were used without further purification. Chromatography was performed with Merck silica gel (mesh 70 to 230) and basic aluminum oxide, deactivated with water and ethanol.

\subsection{Measurements}

${ }^{1} \mathrm{H}$ NMR spectra and ${ }^{13} \mathrm{C}$ NMR spectra were recorded on a Varian unity $300 \mathrm{MHz}$ spectrometer using d-DMSO and $\mathrm{CdCl}_{3}$ as solvents. Elemental analyses were performed on a Heraeus CHN-OS Rapid elemental analyzer. Thermogravimetric analyses (TGA) were conducted on a Du Pont Thermal Analyst 2100 system with a TGA 2950 thermogravimetric analyzer at a heating rate of $20^{\circ} \mathrm{C} / \mathrm{min}$ under nitrogen. Gel permeation chromatography (GPC) analyses were conducted with a Water 1515 separation module using polystyrene as a standard and THF as an eluent. UV-Vis absorption spectra were recorded in dilute THF solutions $\left(10^{-6} \mathrm{M}\right)$ on a HP G1103A spectrophotometer. Thin films for UV-Vis were spin-coated on quartz substrates from THF solutions with a concentration of 1 wt.\%. Fluorescence quantum yields $\left(\Phi_{\mathrm{f}}\right)$ were determined by comparing the integrated PL densities of a reference 9,10-diphenylanthracene in THF (ca $0.5 \times 10^{-6} \mathrm{M}$ ). A BAS 100 electrochemical analyzer with a standard three-electrode electrochemical cell in a $0.1 \mathrm{M}$ tetrabutylammoniumhexafluorophosphate $\left(\mathrm{TBAPF}_{6}\right)$ solution has been used to calculate cyclic voltammetry (CV) measurements at room temperature with a scanning rate of $100 \mathrm{mV} / \mathrm{s}$. During the CV measurements, the solutions were purged with nitrogen for $30 \mathrm{~s}$. A carbon working electrode coated with a thin layer of the polymers, a platinum wire as the counter electrode and a silver wire as a quasireference electrode were used, and $\mathrm{Ag} / \mathrm{AgCl}$ (3 M $\mathrm{KCl})$ electrode served as a reference electrode for all potentials quoted herein. The redox couple of ferrocene/ferrocenium ion $\left(\mathrm{Fc} / \mathrm{Fc}^{+}\right)$was used as an external standard. The corresponding highest occupied molecular orbital (HOMO) levels were calculated using $\mathrm{E}_{\mathrm{ox} / \text { onset }}$ and LUMO values were estimated by the deduction of optical band gaps from HOMO values [24]. The onset potentials were determined from the intersections of two tangents drawn at the rising currents and background currents of the $\mathrm{CV}$ curve. 


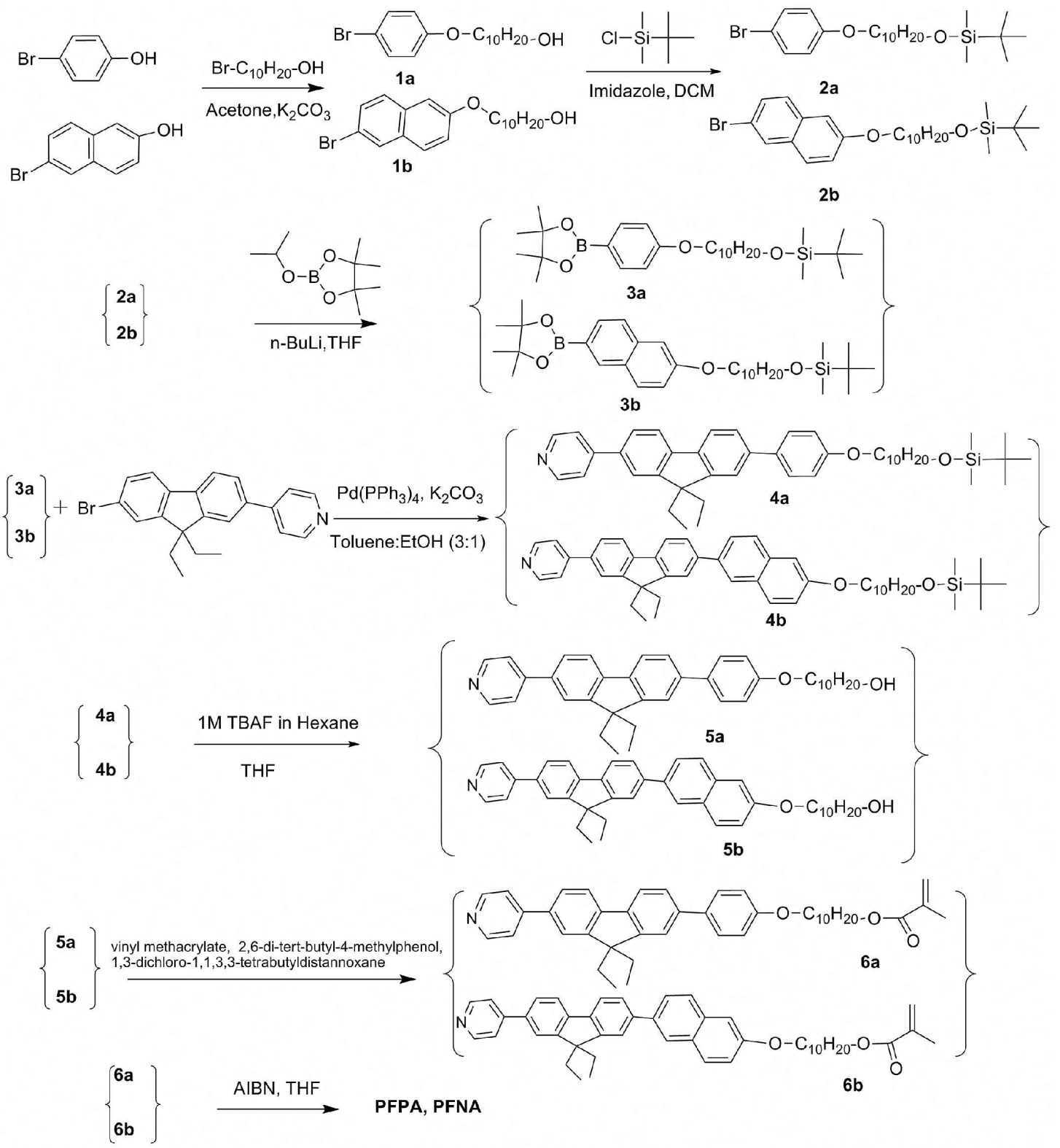

Fig. 1. Synthetic route for PFPA and PFNA.

\subsection{Synthesis}

The general synthetic routes of monomers $6 \mathrm{a}, 6 \mathrm{~b}$ and polymers (PFPA and PFNA) are shown in Fig. 1. Both the polymers PFPA and PFNA have been synthesized by our own procedure [25]. The compound 1a and the compound $1 \mathrm{~b}$ were synthesized by the O-alkylation of $\mathrm{p}$ bromophenol/nepthol which further protected the active $\mathrm{OH}$ by silylation in presence of imidazole to get the compound $2 \mathrm{a}$ and the compound $2 \mathrm{~b}$ followed by boronation reaction in presence of $\mathrm{n}$-BuLi to get the compounds $3 \mathrm{a}$ and $3 \mathrm{~b}$. Further Suzuki coupling of the compound $3 \mathrm{a}$ and the compound 3b, with 4-(7-bromo-9,9-diethyl9H-fluoren-2-yl)pyridine gave the compounds $4 \mathrm{a}$ and $4 \mathrm{~b}$. Desilylation of the compounds $4 \mathrm{a}$ and $4 \mathrm{~b}$ in presence of TBAF gave the monomer precursors $5 \mathrm{a}$ and $5 \mathrm{~b}$ followed by acrylation to form the monomers $6 \mathrm{a}$ and $6 \mathrm{~b}$. The monomer $6 \mathrm{a}$ and 
the monomer $6 \mathrm{~b}$ are polymerized through free radical polymerization using AIBN to get PFPA and PFNA.

10-(4-(9,9-diethyl-7-(pyridine-4-yl)-9H-fluoren-2-yl)phenoxy)decylmethacrylate(6a): Compound 5a (1.3 g, $2.37 \mathrm{mmol})$, 1,3dichloro1, $1,3,3$,tetrabutyldistannoxane (131 mg, $0.23 \mathrm{mmol}$ ), 2,6-di-tert-butyl-4-methylphenol (52 $\mathrm{mg}$, $0.23 \mathrm{mmol}$ ) were taken in a vacuum tight flask and dried by placing under vacuum. Then, vinyl methacrylate $(1.4 \mathrm{~mL}, 11.5 \mathrm{mmol})$ and $1.5 \mathrm{~mL}$ of dry THF were added. The resulting solution was stirred at $50{ }^{\circ} \mathrm{C}$ for $48 \mathrm{~h}$. The product was extracted with dichloromethane followed by washing with brine. The solvent was dried over anhydrous $\mathrm{MgSO}_{4}$ and removed by rotavapor. The crude product was purified by column chromatography on $\mathrm{Al}_{2} \mathrm{O}_{3}$ using dichloromethane as eluent to yield white solid (1.3 g, $89 \%)$. ${ }^{1} \mathrm{H}$ NMR (300 MHz, $\left.\mathrm{CDCl}_{3}\right), \delta: 8.65(\mathrm{~d}, 2 \mathrm{H}), 7.77(\mathrm{t}, 2 \mathrm{H}), 7.50$ to 7.74 $(\mathrm{m}, 8 \mathrm{H}), 6.99(\mathrm{~d}, 2 \mathrm{H}), 6.08(\mathrm{~s}, 1 \mathrm{H}), 5.52(\mathrm{~s}, 1 \mathrm{H})$, $4.12(\mathrm{t}, 2 \mathrm{H}), 3.99(\mathrm{t}, 2 \mathrm{H}), 2.13(\mathrm{q}, 4 \mathrm{H}), 1.92(\mathrm{t}$, $2 \mathrm{H}) 1.63$ to $1.82(\mathrm{~m}, 5 \mathrm{H}), 1.25$ to $1.46(\mathrm{~m}, 12 \mathrm{H})$, $0.37(\mathrm{t}, 6 \mathrm{H}) .{ }^{13} \mathrm{C}$ NMR $\left(75 \mathrm{MHz}, \mathrm{CDCl}_{3}\right), \delta(\mathrm{ppm})$ : $159.1,151.5,150.6,149.1,142.8,140.8,139.6$, $136.9,134.1,128.5,126.4,126.1,125.5,121.9$, $121.6,121.5,120.6,120.5,115.2,68.5,65.2,56.7$, 33.2, 29.9, 29.8, 29.7, 29.6, 29.0, 26.5, 26.3, 18.7, 9.0, MS (FAB): $\mathrm{m} / \mathrm{z}\left[\mathrm{M}^{+}\right] 614$; calc. $\mathrm{m} / \mathrm{z}\left[\mathrm{M}^{+}\right]$ 615.37. Anal. calc. for $\mathrm{C}_{42} \mathrm{H}_{49} \mathrm{NO}_{3}: \mathrm{C}, 81.91 ; \mathrm{H}$, 8.02; N, 2.27. Found: C, 81.42; H, 8.05; N, 2.65 .

Poly[10-(4-(9,9-diethyl-7-(pyridine-4-yl)-9Hfluoren-2-yl)phenoxy)decylmethacrylate]

(PFPA): The polymerization was carried out by the free radical polymerization described as follows. In a Schlenk tube, monomer $6 \mathrm{a}(1.5 \mathrm{~g}$, $2.43 \mathrm{mmol}$ ) was dissolved in $20 \mathrm{wt} . \%$ monomer concentration of dry THF $(7.5 \mathrm{~mL})$ with AIBN (5 mg, 2 mol.\% the monomer concentration) as an initiator. The solution was degassed by three freeze-pump-thaw cycles and then sealed off. The reaction mixture was stirred and heated at $60{ }^{\circ} \mathrm{C}$ for $48 \mathrm{~h}$. After polymerization, the polymer was precipitated into methanol. The precipitated polymer was collected, washed with diethyl ether, and dried under high vacuum. Yield: $1.25 \mathrm{~g}(83.3 \%)$ of PFPA as a white solid. 1H NMR $(300 \mathrm{MHz}$, $\mathrm{CDCl} 3$ ), $\delta$ (ppm): 8.62 (br, s, 2H), 7.68 to 7.51 (br, m, 10H), 6.93 to 6.90 (br, m, 2H), 3.94 (m, s, 4H), 2.04 (br, s, 6H), 1.78 (br, s, 2H), 1.61 to 1.32 (br, m, $12 \mathrm{H}$ ), 0.35 to 0.30 (br, m, 6H). GPC (THF, polystyrene standard): $\mathrm{Mn}=14215 \mathrm{~g} / \mathrm{mol}$, $\mathrm{Mw}=15212 \mathrm{~g} / \mathrm{mol}$, PDI $=1.07$, Anal. calc. for $\mathrm{C}_{42} \mathrm{H}_{49} \mathrm{NO}_{3}: \mathrm{C}, 81.91 ; \mathrm{H}, 8.02 ; \mathrm{N}, 2.27$. Found: $\mathrm{C}$, 82.87; H, 8.15; N, 2.77.

Poly[10-(6-(9,9-diethyl-7-(pyridin-4-yl)-9Hfluoren-2-yl)naphthalen-2-yloxy) decylmethacrylate] (PFNA): Polymer PFNA (Fig. 2) has been synthesized with the same procedure as PFNA by taking monomer $6 \mathrm{~b}$ to yield white solid (yield: $80 \%) 1 \mathrm{H}$ NMR (300 MHz, CDCl3), $\delta$ (ppm): 8.60 (br, s, 2H), 7.61 to 7.49 (br, m, 12H), 6.90-6.87 (br, m, 2H), 3.92 (m, s, 4H), 1.98 (br, s, 6H), 1.80 (br, s, 2H), 1.64 to 1.33 (br, m, 12H), 0.38 to 0.32 (br, m, 6H). GPC (THF, polystyrene standard): Mn $=13,349 \mathrm{~g} / \mathrm{mol}, \mathrm{Mw}=15130 \mathrm{~g} / \mathrm{mol}, \mathrm{PDI}=1.13$. Anal. calc. for $\mathrm{C}_{46} \mathrm{H}_{51} \mathrm{NO}_{3}: \mathrm{C}, 82.97 ; \mathrm{H}, 7.72 ; \mathrm{N}$, 2.10. Found: C, 83.72; H, 7.81; N, 2.27.

\section{Results and discussions}

\subsection{Thermal properties}

The thermal stability of the conjugated homopolymers PFPA, PFNA was investigated by thermogravimetric analysis (TGA), at a heating rate of $10{ }^{\circ} \mathrm{C} \cdot \mathrm{min}^{-1}$ under nitrogen and its results are shown in Fig. 3. The properties of PFPA and PFNA are summarized in Table 1. The TGA analysis indicates that the degradation temperatures (Td) of the polymers with $5 \%$ weight loss (under nitrogen) are $352^{\circ} \mathrm{C}$ and $359^{\circ} \mathrm{C}$ for PFPA and PFNA, respectively. Furthermore, both the polymers have good thermal stability, which is important for electro-optical device fabrication including OLED and its applications. In addition, the imposition of steric hindrance by introducing napthyl can increase the rod-coil chain, which gives an improved thermal stability while resulting in negligible structural defects due to the asymmetric structure. 


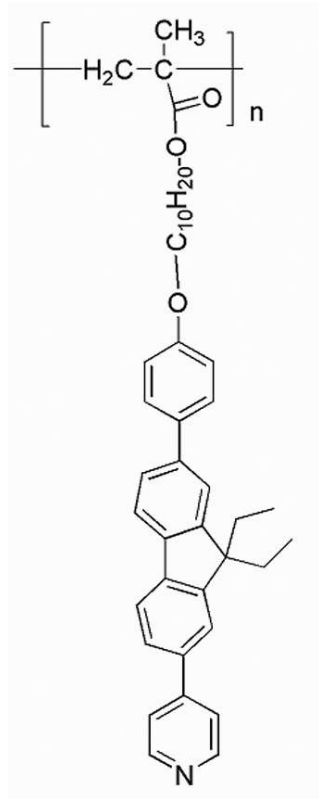

PFPA

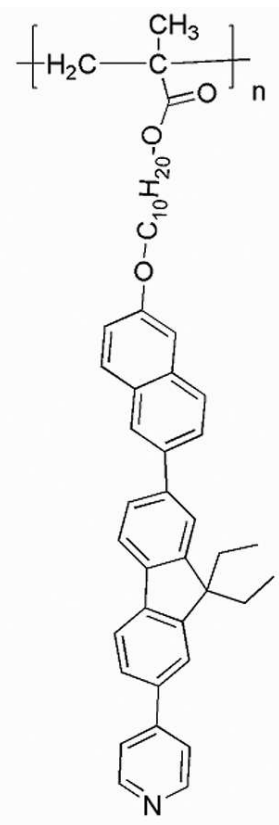

PFNA

Fig. 2. Structure of PFPA and PFNA.

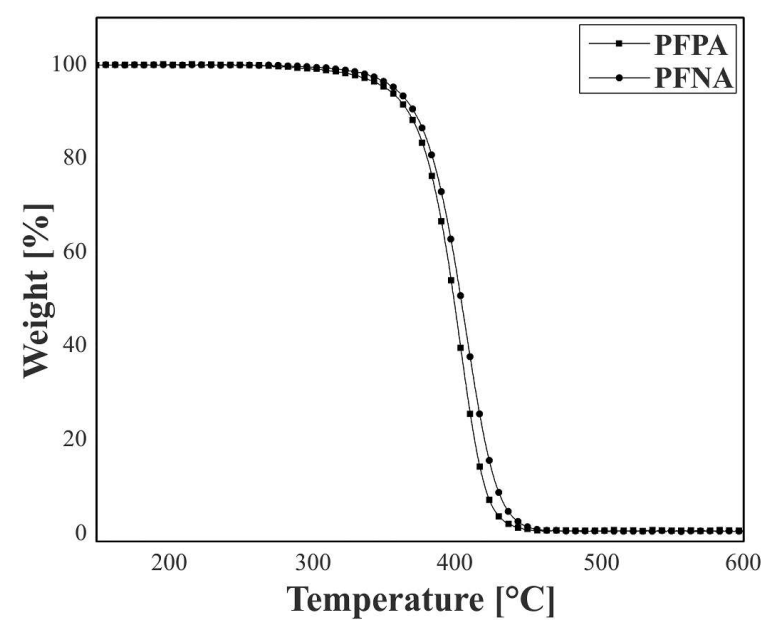

Fig. 3. TGA measurements of homopolymers at a heating rate of $10^{\circ} \mathrm{C} / \mathrm{min}$.

\subsection{Optical properties}

The normalized UV-Vis absorption spectra of the polymers PFPA and PFNA in dilute THF solutions $\left(10^{-6} \mathrm{M}\right)$ and solid films are shown in Fig. 4 and summarized in Table 2. A broad absorption band with absorption maxima $\left(\lambda_{\max }\right)$ at
$335 \mathrm{~nm}$ in solution and $339 \mathrm{~nm}$ in solid film for PFPA and the maxima at $342 \mathrm{~nm}$ (solution), $346 \mathrm{~nm}$ (solid film) for PFNA are observed. The red shift in the solid films in contrast to those in the solutions is attributed to the better $\pi-\pi$ stacking in the solid films than that in the solutions [25, 26]. A red shift in the absorption maxima of PFNA than PFPA, both in the solution and solid films may be due to extended conjugation gained by the introduction of naphthalene group. The normalized PL spectra of both PFPA and PFNA in dilute THF solutions $\left(10^{-6} \mathrm{M}\right)$ and solid films were recorded at an excitation wavelength of $340 \mathrm{~nm}$. Fig. 5 shows the PL spectra of the polymers and the data are documented in Table 2. The fluorescent emissions both in the solution and thin films appear at $404 \mathrm{~nm}$ (sol), $410 \mathrm{~nm}$ (film) for PFPA and $407 \mathrm{~nm}$ (sol), $414 \mathrm{~nm}$ (film) for PFNA, respectively. The emission of blue luminescence in the polymers at very low concentration of $10^{-6} \mathrm{M}$ is due to the introduction of strong chromophoric fluorene group. Furthermore, the photoluminescence quantum efficiencies of the polymers PFPA and PFNA estimated in THF solution by comparing with 
the standard of 9,10-diphenylanthracene are $64 \%$ and $62 \%$, respectively, which indicates that the materials may be used for high technical applications. The stability in the PL spectra of the polymers has been observed with no change after annealing at $150{ }^{\circ} \mathrm{C}$ under vacuum for overnight.

Table 1. Molecular weight and thermal properties of PFPA and PFNA.

\begin{tabular}{ccccc}
\hline Polymer & $\mathrm{M}_{\mathrm{n}}$ & $\mathrm{M}_{\mathrm{w}}$ & PDI & $\mathrm{T}_{\mathrm{d}}\left[{ }^{\circ} \mathrm{C}\right]^{\mathrm{a}}$ \\
\hline \hline PFPA & 14215 & 15212 & 1.07 & 352 \\
PFNA & 13349 & 15130 & 1.13 & 359 \\
\hline
\end{tabular}

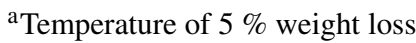

The polymers PFPA and PFNA were almost equivalent from the optical point of view because they displayed similar photophysical characteristics disregard to the small bathochromic shift in their absorption and PL spectra.

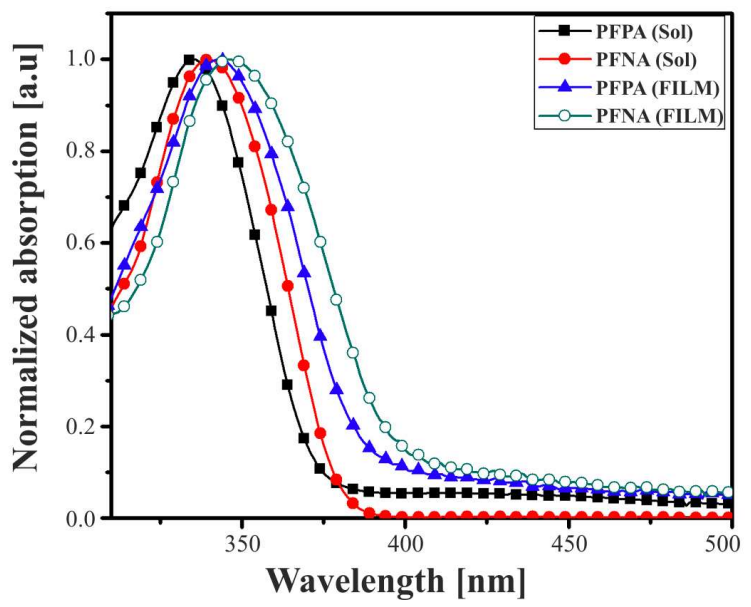

Fig. 4. Normalized absorption spectra of polymers in dilute THF solutions $\left(10^{-6} \mathrm{M}\right)$ and solid films.

\subsection{Electrochemical properties}

In order to get a deeper insight into the electrochemical properties of the polymers, CV measurements were performed (Fig. 6) and the results were summarized in Table 2. The highest occupied molecular orbital (HOMO) levels were calculated according to the following equation: $\mathrm{HOMO}=\left[-\left(\mathrm{E}_{\text {onset }}-0.45\right)-4.8\right] \mathrm{eV}$, where $0.45 \mathrm{~V}$ is the value for ferrocene versus $\mathrm{Ag} / \mathrm{Ag}^{+}$and

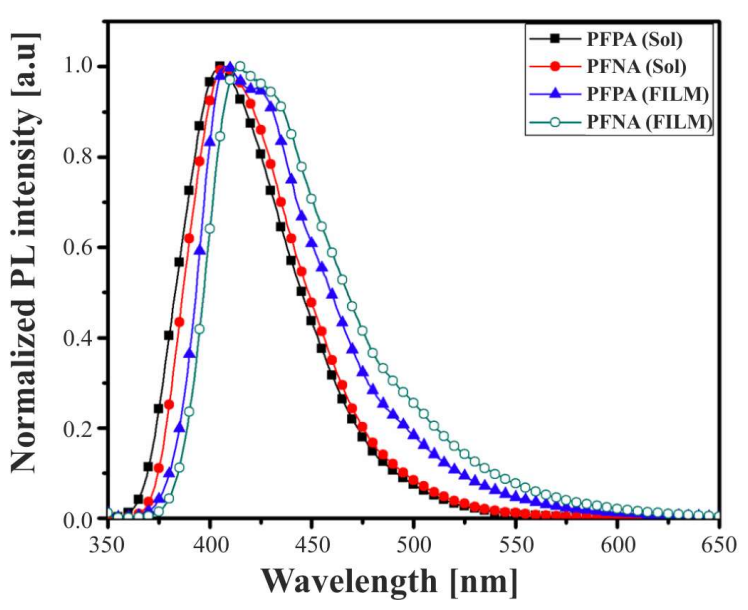

Fig. 5. Normalized PL spectra of homopolymers PFPA and PFNA in dilute THF solutions $\left(10^{-6} \mathrm{M}\right)$ and solid films.

$4.8 \mathrm{eV}$ is the energy level of ferrocene below the vacuum [27-29] and LUMO values were estimated by the deduction of optical band gaps from HOMO values. In addition, the onset potentials were determined from the intersections of two tangents drawn at the rising and background currents of the CV curves. Owing the presence of the same central fluorene chromophore both in PFPA and PFNA, the compounds showed similar oxidation onset of $0.96 \mathrm{~V}$ and $0.93 \mathrm{~V}$ with HOMO values of -5.31 and $-5.28 \mathrm{eV}$, respectively. The optical band gaps estimated from the absorption onsets of PFPA and PFNA in solid films were $3.09 \mathrm{eV}$ and $3.10 \mathrm{eV}$, respectively. The respective LUMO were calculated by subtracting optical band gap from the $\mathrm{HOMO}$ and were found $-2.22 \mathrm{eV}$ and $-2.18 \mathrm{eV}$, respectively.

\section{Conclusions}

Two chromophoric homo-polymers (PFPA and PFNA) containing pendant pyridine and chromophoric 9,9-diethylfluorene moiety extended with conjugated phenyl (PFPA) and naphthalene (PFNA) have been synthesized. The formations of monomers and rod-coil homopolymer were characterized by ${ }^{1} \mathrm{H}$ NMR spectra; ${ }^{13} \mathrm{C}$ NMR spectra and the molecular weight were calculated by GPC. The extended decoxy groups in 
Table 2. Optical and Electrochemical properties.

\begin{tabular}{|c|c|c|c|c|c|c|c|c|}
\hline \multirow{2}{*}{ Polymer } & \multicolumn{2}{|c|}{ Solution } & \multicolumn{2}{|c|}{ Film } & \multirow{2}{*}{$\begin{array}{c}\mathrm{E}_{\mathrm{OX}} / \text { onset } \\
{[\mathrm{V}]^{\mathrm{a}}}\end{array}$} & \multirow{2}{*}{$\begin{array}{c}\text { HOMO } \\
{[\mathrm{eV}]^{\mathrm{b}}}\end{array}$} & \multirow{2}{*}{$\begin{array}{c}\mathrm{E}_{\mathrm{g}} \\
{[\mathrm{eV}]}\end{array}$} & \multirow{2}{*}{$\begin{array}{l}\text { LUMO } \\
{[\mathrm{eV}]^{\mathrm{c}}}\end{array}$} \\
\hline & $\begin{array}{c}\lambda_{\max } \\
(\text { abs in nm) }\end{array}$ & $\begin{array}{c}\lambda_{\max } \\
(\mathrm{PL} \text { in } \mathrm{nm})\end{array}$ & $\begin{array}{c}\lambda_{\max } \\
(\text { abs in nm) }\end{array}$ & $\begin{array}{c}\lambda_{\max } \\
(\mathrm{PL} \text { in } \mathrm{nm})\end{array}$ & & & & \\
\hline PFPA & 335 & 404 & 342 & 410 & 0.96 & -5.31 & 3.09 & -2.22 \\
\hline PFNA & 339 & 407 & 346 & 414 & 0.93 & -5.28 & 3.10 & -2.18 \\
\hline
\end{tabular}

${ }^{\mathrm{a}}$ Onset oxidation and reduction potentials measured by cyclic voltammetry in solid films

${ }^{\mathrm{b}} \mathrm{HOMO}=\left[-\left(\mathrm{E}_{\text {onset }}-0.45\right)-4.8\right] \mathrm{eV}$, where $0.45 \mathrm{~V}$ is the value for ferrocene versus $\mathrm{Ag} / \mathrm{Ag}^{+}$and $4.8 \mathrm{eV}$ is the energy level of ferrocene below the vacuum

${ }^{\mathrm{c}} \mathrm{LUMO}$ has been calculated from optical band gap

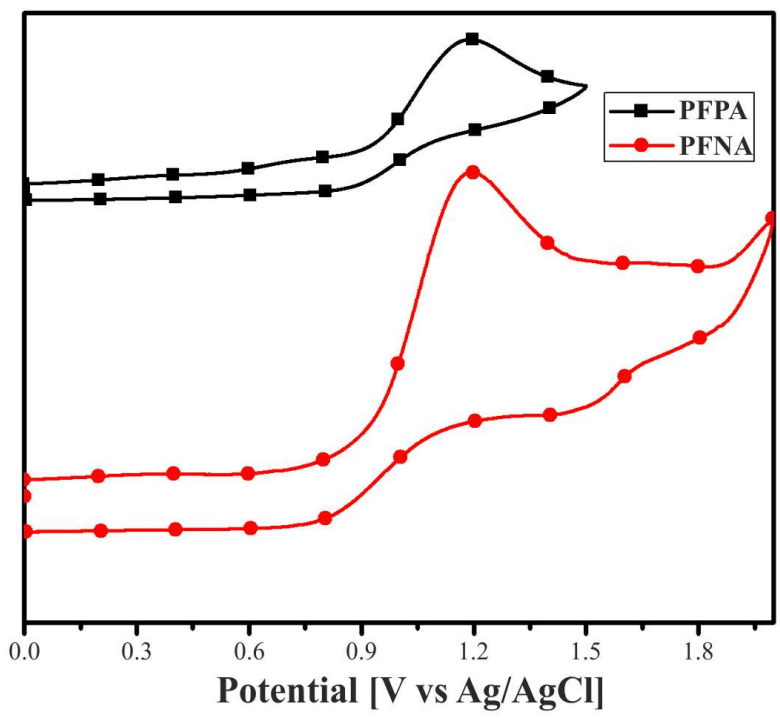

Fig. 6. Cyclic voltammograms of polymers in solid films at a scan rate of $100 \mathrm{mV} / \mathrm{s}$.

the conjugated segments imparted the resulting polymers with excellent solubility in common organic solvents like hexane, dichloromethane, toluene, ethyl acetate, THF, etc. The polymers PFPA and PFNA showed good thermal stability and exhibited stable luminescent characteristics with a quantum yield of 0.64 and 0.62 , respectively. The optical and electrochemical data revealed that these polymers could be stable candidates for blue light emitting electronic devices. The PL spectra of the polymers have shown better stability on annealing. Furthermore, the electro-optical characteristics can be well tuned by different conjugated substituents including phenyl, naphthalene, etc., in the chromophoric moiety.

\section{Acknowledgements}

The financial supports of this project provided by the Department of Chemistry, the National Institute of Science and Technology, Berhampur, Odisha, are greatly acknowledged.

\section{References}

[1] Feng X.J., Chen S.F., Ni Y., Wong M.S., Lam M.M.K., CheAH K.W., LAI G.Q., Org. Electron, 15 (2014), 57.

[2] Tsuji M., Saeki A., Koizumi Y., Matsuyama N., Vijaykumar C., SeKi S., Adv. Funct. Mater, 24 (2014), 28.

[3] LAM K.H., Foong T.R.B., Zhang J., GRimsdale A.C., LAM Y. M., Org. Electron, 15 (2014), 1592.

[4] Vilbrandt D., Gassmann, A., Seggern H. V., REHAN, M., Macromolecules, 49 (2016), 1674.

[5] Jou J.-H., Kumar S., Agrawal A., Li T.-H., SAHOO S.,J. Mater. Chem. C, 3 (2015), 2974.

[6] Beaupre S., Lellerc M., Adv. Funct. Mater., 12 (2002), 192.

[7] BeAupre S., LeCLERC M., Macromoleules, 36 (2003), 8986.

[8] Gao Z.Q., Mi B.X., Chen C.H., Cheah K.W., Cheng Y.K., Wen W.S., Appl. Phys. Lett., 90 (2007), 1235.

[9] Yuan C., Saito S., CaMacho C., Irle S., Hisaki I., Yamaguchi S., J. Am. Chem. Soc, 135 (2013), 8842.

[10] Usluer Ö., Demic S., Kus M., Özel F., SARCiftci N.S., J. Lumin., 146 (2014), 6.

[11] Lu C., Wang H., Wang X., Li Y., OiU T., He L., Li X., J. Appl. Polym. Sci., 117 (2010), 517.

[12] ZHENG C.-J., ZHAO W.-M., WANG Z.-Q., HuANG D., YE J., OU X.-M., ZHANG X.-H., LEE C.-S., LEE S.T., J. Mater. Chem., 20 (2010), 1560.

[13] Zhuang S., Shangguan R., Huang H., Tu G., Wang L., Zhu X., Dyes Pigments, 101 (2014), 93.

[14] Pan B., Wang B., Wang Y., Xu P., Wang L., Chen J., MA D., J. Mater. Chem. C, 2 (2014), 2466.

[15] Loy D.E., Koene B.E., Thompson M.E., $A d v$. Funct. Mater., 12 (2002), 245. 
[16] Friend R.H., Gymer R.W., Holmes A.B., BuRRoughes J.H., MARKS R. N, TALIANi C., BRADELY D.D.C., Santos D.A.D., BREdes J.L., LOGDLUND M., SALANECK W.R., Nature, 397 (1999), 121.

[17] Bernius M.T., Inbasekaran M., O'Brien J., WU W., Adv. Mater., 12 (2000), 1737.

[18] Pei Q., Yang Y., J. Am. Chem. Soc., 118 (1996), 7418.

[19] Muller C. D., Falcou A., Reckefuss N., RoJAhn M., Wiederhirn V., Rudati P., Frohne H., Nuy Ken O., Becker H., MeErholz K., Nature, 421 (2003), 829.

[20] Saxena V., Shirodkar V.S., J. Appl. Polym. Sci., 77 (2000), 1051.

[21] SU H.-J., Wu F.-I., SHu C.-F., Macromolecules, 37 (2004), 7197.

[22] Su H.-J., Wu F.-I., Tseng Y.-H., Shu C.-F., Adv. Funct. Mater, 15 (2005), 1209.

[23] Xia Y., Zhong C., Li B., Wu H., CAO Y., FAN D., J. Appl. Polym. Sci., 125 (2012), 1409.
[24] Sahu D., Tsai C.-H., WeI H.-Y., Ho K.-C., Changc F.-C., Chu C.-W., J. Mater. Chem., (22) 2012, 7945.

[25] Sahu D., KeKuda D., Chu C.-W., DSSG-2013, National Institute of Science and Technology, $29^{\text {th }}$ November - $1^{\text {st }}$ December, 2013, p 33.

[26] Sahu D., Padhy H., Patra D., Kekuda D., Chu C.-W., Chiang I.H., Lin H.-C., Polymer, 51 (2010), 6182.

[27] Sahu D., Padhy H., Patra D., Yin J.-F., Hsu Y.-C., LIN J.-T., LU K.-L., WEI K.-H., LIN H.-C., Tetrahedron, 67 (2011), 303.

[28] De Leeuw D.M., Simenon M.M.J., Brown A.R., EINERHAND R.E.F., Synth. Met., 87 (1997), 53.

[29] Yang P.-J., Wu C.-W., SAhu D., Lin H.-C., Macromolecules, 4 (2008), 9692.

Received 2016-03-08 Accepted 2017-01-25 